\title{
STRUCTURAL BEHVAIOR OF REINFORCED CONCRETE BEAMS CAST USING BLENDED CEMENT
}

\author{
Mounir M. Kamal ${ }^{1}$, Mohamed A. Safan ${ }^{1}$, Amr A. Elboghdady ${ }^{2}$ \\ ${ }^{1}$ Civil Engineering Department, Faculty of Engineering, Menoufia University, \\ Egypt \\ ${ }^{2}$ Ministry of Water Resources and Irrigation, Dakahlya, Egypt
}

\begin{abstract}
An experimental study has been carried out in the present work to study the structural behavior of reinforced concrete beams cast using blended cement concrete. The eight tested beams were 160 $\mathrm{cm}$ long $\times 20 \mathrm{~cm}$ deep $\times 12 \mathrm{~cm}$ wide. The test beams were reinforced with two different steel reinforcement ratios of $0.70 \%$ and $1.0 \%$. Two beams were control beams cast using Portland cement and the other six beams were cast using blended cement incorporating 5\%, 10\% and 15\% dolomite powder as cement replacement. To achieve the aim of the research; all beams were tested under 4-point loading until failure and the following measurements have been recorded during testing the beams for each load increment; the compressive and tensile strains in concrete and steel, and mid-span deflection. The propagation of cracks was marked on the side and soffit of the beam. The results of monitoring the tensile and compressive strains, mid-span deflection and cracking pattern are presented. The results demonstrated that the 5 percent replacement ratio did not influence the structural behavior, while the ultimate loads and stiffness were reduced as the 10 and 15 percent replacement ratios. On the other hand, the cracking characteristics and failure mode were not influenced by the cement replacement.

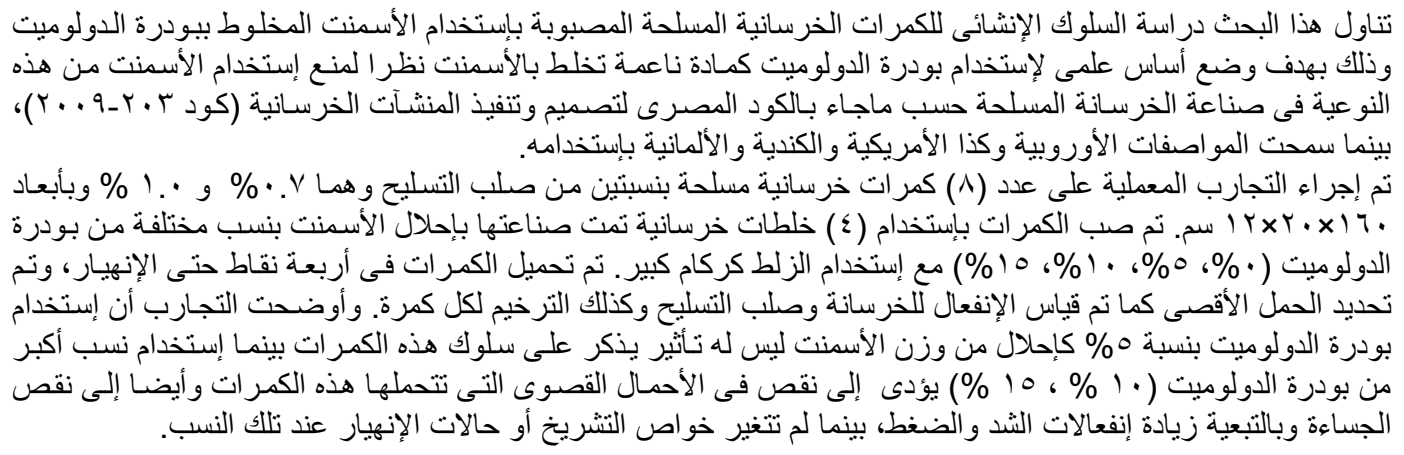

Keywords: DP replacement ratio, RC beams, crack pattern, deflection, strain.

\section{INTRODUCTION}

It has been well established that the properties of concrete depend on the quantities and quality of its constituents, especially cement as the active component of concrete with usually the greatest unit cost. On the other hand, cements are generally needed to provide adequate levels of strength and durability. Therefore, the selection and proper use of cement is rather important to achieve balance between cost and the desired properties of the concrete mix.

World-production of Portland cement has increased steadily in recent years, reaching 3.43 billion tones in 2011. Cement production, however, has very high energy demands $(850 \mathrm{kcal}$ per $\mathrm{kg}$ of clinker) and alters the environment where the prime materials are quarried and emits greenhouse gases into the atmosphere $\left(\mathrm{NO}_{2}, \mathrm{SO}_{2}, \mathrm{CO}_{2}\right)$. More specifically, the cement industry emits $850 \mathrm{~kg}$ of $\mathrm{CO}_{2}$ for every ton of cement which accounts for $7 \%$ of world-wide $\mathrm{CO}_{2}$ emissions $[1,2]$.

Ordinary Portland Cement (OPC) is the most common type of cement in general use around the world because it is a basic ingredient of concrete, mortar and most non-specialty grout. The need of decreasing the amount of cement uses in civil engineering infrastructure is stressing with the ever increasing demands. A recent approach to overcome such problem was to use qualified wastes from the 
industry to replace specified fractions of OPC. Such replacement should not adversely affect the performance of cement as a bonding material. Economic and environmental concerns by utilizing industrial wastes, reducing carbon dioxide emissions, and lowering energy requirements for Portland cement are expected outcomes of using blended cements combining OPC and the replacing fine materials. Therefore, using blended cement in civil engineering infrastructure has been identified as an important focus in the field of scientific research.

There are different standards for the classification of Portland cement. The two major standards are the ASTM C150 standard [3], used primarily in the U.S. and the European EN-197-1 standard [4]. The European Cement Standard EN 197-1[4] and the Egyptian Standards Specification E.S.S, 4756-1/2009 [5] described 27 types of common cement classified under five groups as follows:

I. Portland cement: comprising Portland cement and up to $5 \%$ of minor additional constituents.

II. Portland composite cement: Portland cement and up to $35 \%$ of other single constituents.

III. Blast furnace cement: Portland cement and higher percentages of blast furnace slag.

IV. Pozzolanic cement: Portland cement and up to $55 \%$ of pozzolanic constituents.

V. Composite cement: Portland cement, blast furnace slag and pozzolana or fly ash.

Portland-limestone cement (PLC) has been successfully used in Europe for over 25 years. While regular Portland cement may contain up to $5 \%$ limestone, PLC is manufactured by grinding Portland cement clinker with $6 \%$ and $15 \%$ limestone. The clinker used to make PLC is the same clinker that is used to manufacture regular Portland cement. The performance of PLC is dependent on the quality of the limestone. In recognition of this fact, limestone used in PLC is tested for calcium carbonate content, clay content and total organic carbon content. The $15 \%$ limestone limit applied to PLC in Canada is well below the maximum limit of $35 \%$ permitted in European standards [6]. The Egyptian Code for the design and construction of reinforced concrete structures ECP 203-2009 [7] did not allow the use of Portland limestone cements PLC (CEM II/A-L, CEM II/B-L, CEM II/A-LL, and CEM II/B-LL) in reinforced and prestressed concrete. Dolomite powder is an inexpensive and useful calcium supplement to be added to concrete and mortar production as sand or cement replacing material. The powder differs chemically depending on the parent dolomite stone which depends on the locality, degree of metamorphism and other factors.

The rheological properties and short term strength for single, binary and ternary systems of silica fume, fly ash and dolomite powders replacing Portland cement has been reported in Ref. [8, 9]. Self- compacting concrete mixes selected on compressive strength criterion were used by Safan [10] to study the flexure and shear strength of reinforced concrete beams. Also, these mixes were used to prepare reinforced concrete beams that were subjected to severe corrosive environment and tested in flexure [11]. The results obtained that far were very encouraging for implementing binary systems of dolomite powder and either silica fume or fly ash to replace Portland cement in SCC mixes. Hotton et al. [12] and Thomas et al. [13] reported that PLCs were the largest single type of cement currently used in the European countries in a variety of works including pavement works and precast concrete. They reported that the benefits of PLCs included: reduced greenhouse gas emissions due to reduced $\mathrm{CO}_{2}$ as the clinker factor in the cement is reduced, improved workability and pumpability, similar physical performance to current cements when the cements are properly optimized and similar durability to chloride ingress and alkali silica reaction.

In the current work eight RC reinforced beams with two different steel reinforcement ratios of $0.70 \%$ and $1.0 \%$ cast using selected concrete mixes containing different dolomite powder replacement ratios $(0,5,10,15$ percent by weight of cement $)$ were tested in flexure under four-point loading until failure taking into account the following test parameters; the steel reinforcement ratio and the content of the dolomite powder. The structural performance of test beams was thoroughly described by measuring the mid-span deflection and the strain in both the steel and concrete during the whole course of loading. Also the cracking patterns, cracking loads and ultimate loads were all recorded.

\section{AIM OF THE RESEARCH}

The aim of the research is to study the structural behavior of RC beams cast using blended cement concrete. Eight beams are designed to study the effect of using dolomite powder on the structural behavior of RC beams for different rebar diameters and different concrete mixes incorporating dolomite powder (DP) replacing different weight ratios of Portland cement

\section{MATERIALS AND EXPERIMENTAL WORK}

A total of eight beams were cast and tested under four-point bending test as a part of the work done in reference [14]. The beams were divided into four groups A, B, C and D. Each group consisted of two reinforced beams, one of them (B10/0) reinforced with two steel bars of $10 \mathrm{~mm}$ diameter $(0.7 \%$ steel reinforcement ratio) while the other (B12/0) was reinforced with two steel bars of $12 \mathrm{~mm}$ diameter (1.0\% steel reinforcement ratio). Group A was control test specimens with no DP replacement. The other six beams were cast with three concrete mixes incorporating DP at 5, 10 and 15 percent replacement 
ratios. Accordingly, the structural behavior was studied in this work by testing beams taking into account the following test parameters; the steel reinforcement ratio and the content of the dolomite powder.

The following sections provide detailed description of the materials used, design of test specimens and testing procedures.

\subsection{Materials}

Concrete: four concrete mixes were proportioned using ordinary Portland cement CEM I N 42.5 (C), gravel $(\mathrm{G})$ with a maximum nominal size of 19.1 $\mathrm{mm}$, graded sand (S), dolomite powder (DP), and tap water (W). The concrete mix proportions were calculated using the absolute volume method. The calculations are based on a saturated surface dry condition of the aggregates. The weight of the different constituents per cubic meter of concrete are given in Table (1). Beams B10/0, B12/0 were cast using concrete mix (1), beams B10/5 and B12/5 were cast using concrete mix (2), beams B10/10 and B12/10 were cast using concrete mix (3) and beams B10/15, B12/15 were cast using concrete mix (4). Three cubes $100 \times 100 \times 100 \mathrm{~mm}$ and three prisms 100x100x500 mm were cast and tested after 28 days to determine the mechanical properties for each mix including the compressive strength $\left(f_{c}^{\prime}\right)$ and modulus of rupture $\left(f_{r}\right)$. Table (2) shows the mechanical properties of the four mixes at 28 days.

Steel: Deformed high tensile steel bars with a nominal diameter of 10 and $12 \mathrm{~mm}$ were used as longitudinal reinforcement with a yield stress of 570 and520 $\mathrm{MPa}$, respectively. The transverse reinforcement consisted of 8-mm mild steel stirrups with a yield stress of $320 \mathrm{MPa}$.

Table (1): Constituents of the concrete mix $\left(\mathrm{kg} / \mathrm{m}^{3}\right)$

\begin{tabular}{|c|c|c|c|c|c|}
\hline Mix & C & G & S & DP & W \\
\hline 1 & 400 & 1177 & 590 & 0 & 210 \\
\hline 2 & 380 & 1176 & 589 & $20.0(5 \%)$ & 210 \\
\hline 3 & 360 & 1174 & 588 & $40.0(10 \%)$ & 210 \\
\hline 4 & 340 & 1172 & 588 & $60.0(15 \%)$ & 210 \\
\hline
\end{tabular}

Table (2): Concrete mechanical properties

\begin{tabular}{|c|c|c|c|c|}
\hline Mix No. & $\begin{array}{c}\text { Cement content } \\
\left(\mathrm{kg} / \mathrm{m}^{3}\right)\end{array}$ & DP rep. \% & $\begin{array}{c}f_{c}^{\prime} \\
(\mathrm{MPa})\end{array}$ & $\begin{array}{c}f_{r} \\
(\mathrm{MPa})\end{array}$ \\
\hline 1 & 400 & 0 & 28.2 & 3.5 \\
\hline 2 & 380 & 5 & 28.0 & 3.5 \\
\hline 3 & 360 & 10 & 26.1 & 3.4 \\
\hline 4 & 340 & 15 & 23.8 & 3.2 \\
\hline
\end{tabular}

\subsection{Design Of Test Beams}

The test specimens included a total of eight beams $(120 \times 200 \times 1600 \mathrm{~mm})$. The beams were divided into four groups A, B, C and D. Every group consisted of two reinforced beams, one of them was reinforced with two steel bars of $10 \mathrm{~mm}$ diameter
(0.7\% steel reinforcement ratio) at a depth of 179 $\mathrm{mm}$ and $8 \mathrm{~mm}$ closed steel stirrups at $80 \mathrm{~mm}$ centerto-center spacing running only along the shear span. The other beam was reinforced with two steel bars of $12 \mathrm{~mm}$ diameter (1.0\% steel reinforcement ratio) at a depth of $178 \mathrm{~mm}$ and reinforced in shear as the first beam. Group A was control test specimens with no DP replacement. The other six beams were cast with 
three concrete mixes incorporating DP at 5, 10 and 15 percent replacement ratios. Table (3) shows the details of the test beams groups while Figure (1) shows the dimensions and reinforcement details of test specimens.

Table (3): Details of test beams

\begin{tabular}{|c|c|c|c|c|}
\hline Group & Beam Code & Concrete mix. & DP rep. ratio & Bottom reinf. \\
\hline \multirow{2}{*}{ A } & B10/0 & \multirow{2}{*}{1} & 0 & $2 \phi 10$ \\
\hline & B12/0 & & 0 & $2 \phi 12$ \\
\hline \multirow{2}{*}{ B } & B $10 / 5$ & \multirow{2}{*}{2} & 5 & $2 \phi 10$ \\
\hline & B12/5 & & 5 & $2 \phi 12$ \\
\hline \multirow{2}{*}{$\mathrm{C}$} & B10/10 & \multirow{2}{*}{3} & 10 & $2 \phi 10$ \\
\hline & B12/10 & & 10 & $2 \phi 12$ \\
\hline \multirow{2}{*}{$\mathrm{D}$} & B10/15 & \multirow{2}{*}{4} & 15 & $2 \phi 10$ \\
\hline & B12/15 & & 15 & $2 \phi 12$ \\
\hline
\end{tabular}

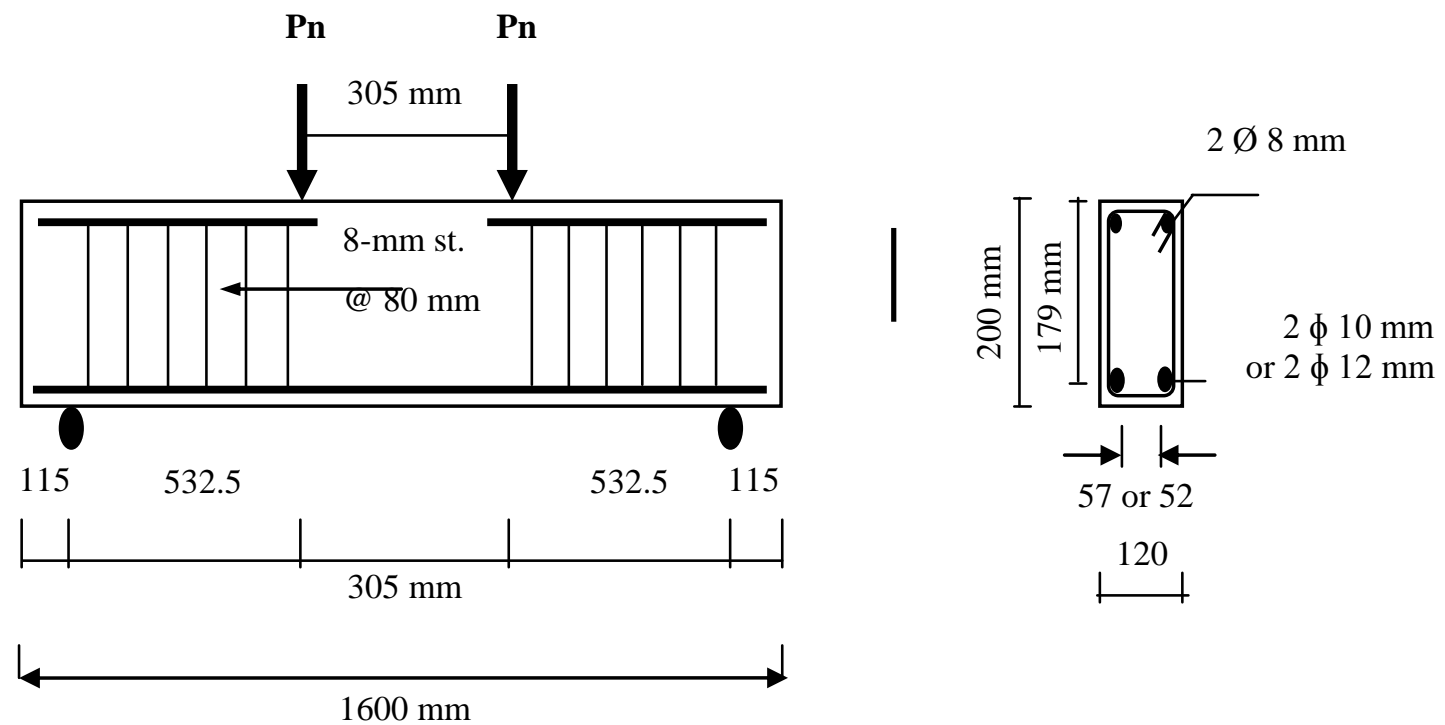

Fig. (1): Dimensions and reinforcement details of test specimens 


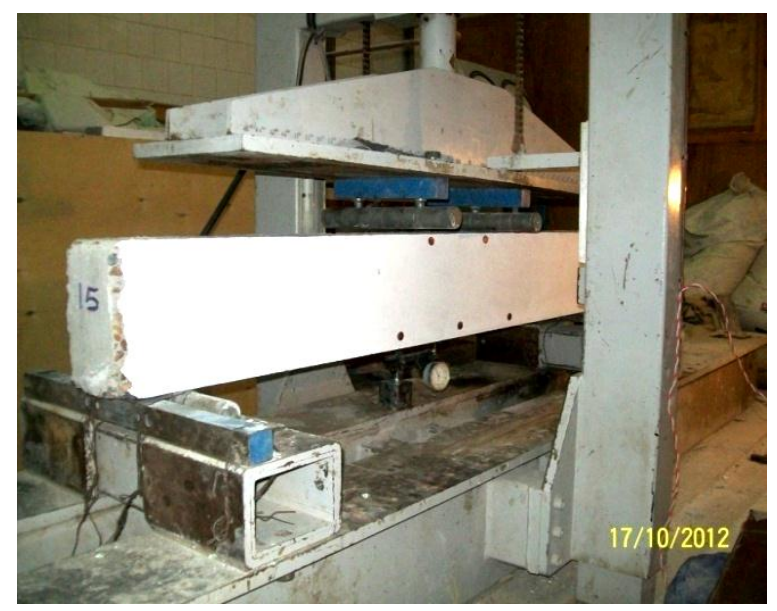

Fig (2): Test setup and position of demec points

\subsection{Preparation and Testing of Beams}

Tight wooden forms were prepared to cast the eight reinforced concrete beams with a cross section of $120 \times 200 \mathrm{~mm}$ and $1600 \mathrm{~mm}$ length. The forms were designed in such a way to ensure water tightness and easy stripping. The inside faces of the forms were coated with grease before concreting. The reinforcements were then placed in position. Supporting steel bars were used to hold the reinforcement at the proper position and were soon removed after concrete was poured. The forms were left in the laboratory atmosphere after casting. After

24 hours, the beams were removed from moulds and cured. They were cured by covering them with wet cloth sheets for 28 days. Four days before testing, all beams were painted in white to facilitate detection of cracks during testing. Two days before testing, demec discs were fixed in position to measure concrete strains in the constant moment region. The tensile strain at the level of reinforcement was measured as well as the compression strain 10 $\mathrm{mm}$ below the extreme compression fiber. Figure (2) shows the test set up and position of demec pointes, while Figure (3) shows strain measuring with a demountable strain gage. A dial gage was used to measure the mid-span deflection as shown in Figure (2)

All beams were tested to ultimate load in fourpoint loading over a simple span of $1370 \mathrm{~mm}$ and a shear span of $532.5 \mathrm{~mm}$ providing a shear span-to depth ratio of 3.0. Both ends of the beam were free to rotate and translated under load. The load was applied by means of a $100 \mathrm{kN}$ capacity flexural machine. The machine is equipped with a digital control console. The load was applied in increments of $2.0 \mathrm{kN}$ until failure. For every increment of load, four readings were recorded (left and right center of beam tensile strain at the level of reinforcement steel, compressive strain about mid span and deflection at middle span were recorded. As the load increased,

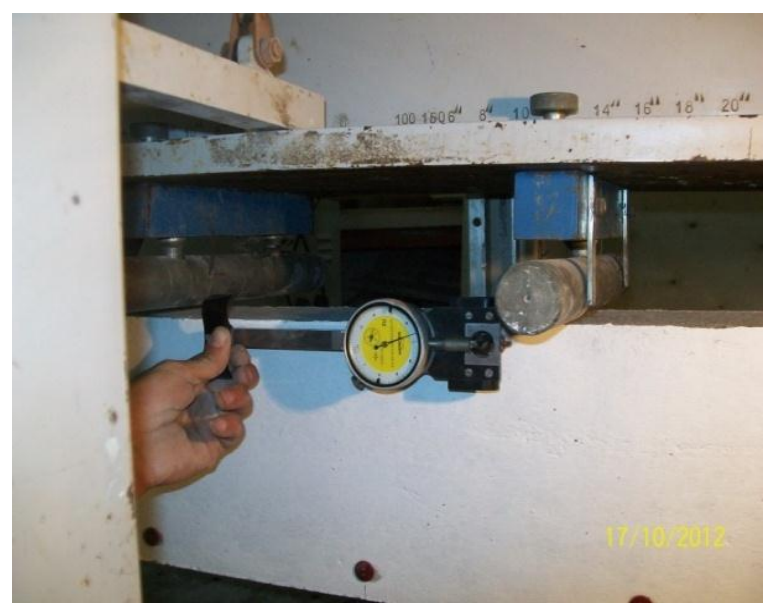

Fig (3): Stain measuring with strain gage

the side face of the beam (front face) was optically inspected to record the load at the first visible crack. Also crack propagation was recorded after each load increment. The load was increased until failure of the beam.

\section{TEST RESULTS AND DISCUSSIONS \\ 4.1 Cracking Patterns}

Figures (4 and 5) show the cracking patterns as mapped at failure of the test beams. It can be seen that the cracking patterns are typically the same independent of the composition of concrete mix and consequently the DP replacement ratio. In these beams cracking was initiated within the maximum moment region. Flexure cracks propagated upwards. As the load level increased, other flexure cracks initiated and propagated upwards outside the maximum moment region. In all these beams, failure took place upon yielding of the steel reinforcement followed by crushing of concrete under either of the two applied loads. Failure was preceded by the formation of diagonal shear cracks near the end supports. It was interesting to see that the total number of cracks at failure in beam B10/10 was (20) compared to (19) in the beam B10/0. Also, the total number of cracks in beam B12/5, B12/10 and B12/15 was (20, 18 and 15 , respectively) compared to (14) in the beam B12/0. It can be concluded that the replacement of cement by DP had no negative impact on the structural behavior of test beams in terms of cracking characteristics and crack spacing.

\subsection{Load-Deformation Response}

Figures (6 and 7) show the load midspan deflection response for the tested beams to identify the influence of the test parameters on the structural performance of these beams. The figures show the load-deflection response for the eight beams with different DP replacement ratios. It can be seen that

the load - deflection response was almost independent of the DP replacement ratio for the two 
reinforcement ratios investigated. While beams B10/5 and B12/5 showed a slightly higher stiffness

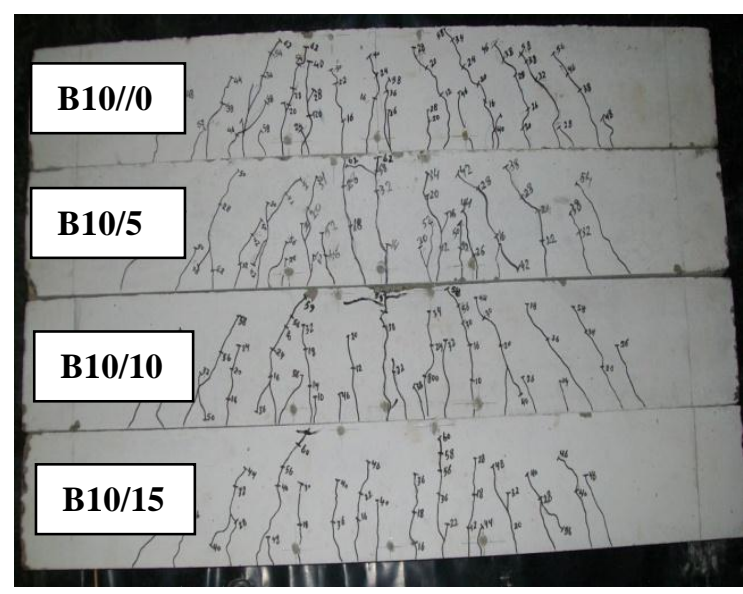

Fig. (4) Side Crack pattern for B10/0, B10/5, B10/10 and $\mathrm{B} 10 / 15$

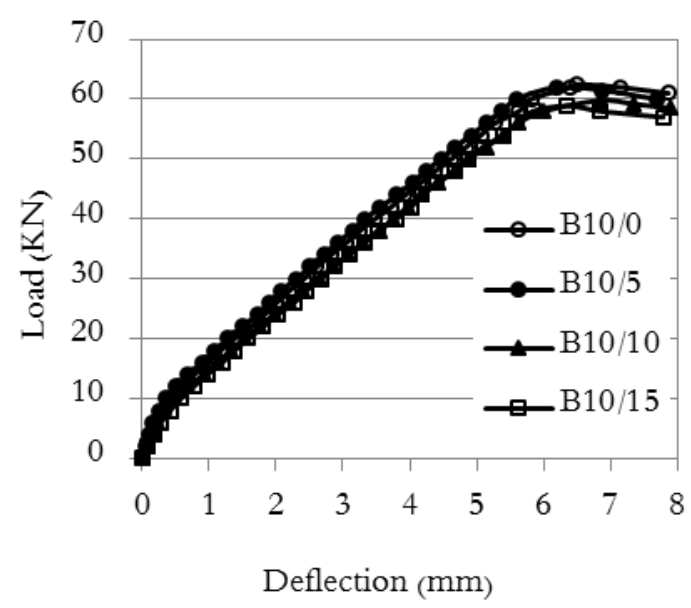

Fig. (6) Measured deflection $\left(d_{b}=10 \mathrm{~mm}\right)$

The tensile strain was measured at the level of counterpart control beams (B10/0, B12/0), the stiffness was slightly lower as the DP ratio increased to 10 and 15 percent. All the curves showed typical response characterized by three distinct stages precracking, postcracking and yieldingthe steel bars. The strain was measured between three demic points fixed at a gage length of $200 \mathrm{~mm}$. Thus the strain measurements covered a length of $400 \mathrm{~mm}$ extending beyond the $305 \mathrm{~mm}$ maximum moment region. The tensile strains measured to the left and to the right with respect to the beam center are shown in Figures

$(8-11)$. These measurements were utilized to calculate the tensile stress in the steel bars

result was attributed to the development of more flexure cracks in the maximum moment region in during the whole course of loading compared to.

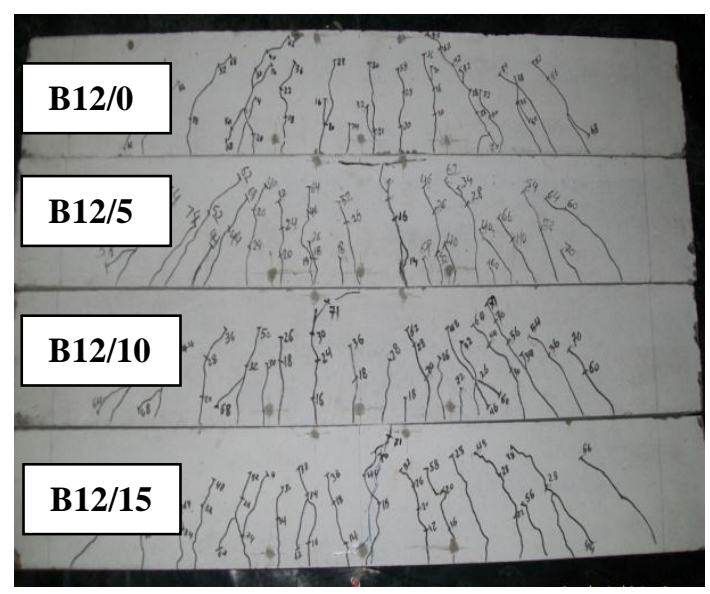

Fig. (5) Side Crack pattern for B12/0, B12/5, B12/10, and B $12 / 15$

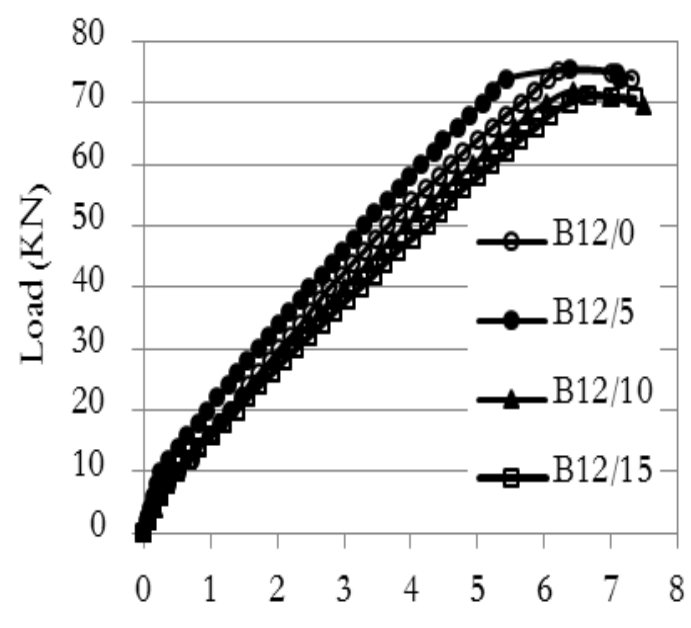

Deflection (mm)

c Fig. (7) Measured deflection $\left(d_{b}=12 \mathrm{~mm}\right)$

three regions denoting the precracking, postcracking and yielding stages.

Figures $(12,13)$ show the measured compressive strain about the mid-span of test beams. Excessive compressive strains were developed in the control beams at failure due to concrete crushing as can be seen in these figures. In these beams it can be seen that the compressive strain tended to attain relatively higher values at the same load levels as when the DP replacement ratio was 10,15 percent. The same remark was also true in case of the tensile strain. This

case of these beams yielding increased tensile strain, deflection and consequently compressive strain. 


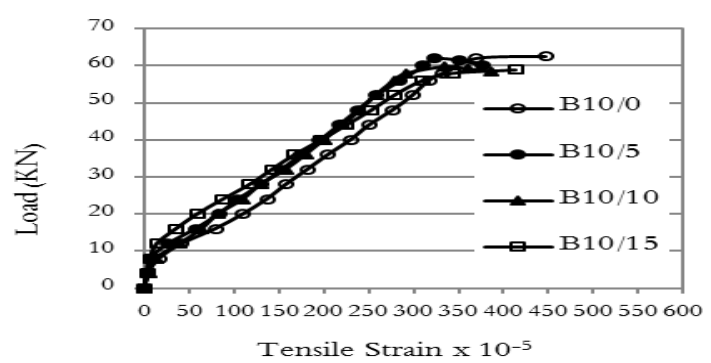

Fig. (8) Measured left side tensile strain $\left(d_{b}=10 \mathrm{~mm}\right)$

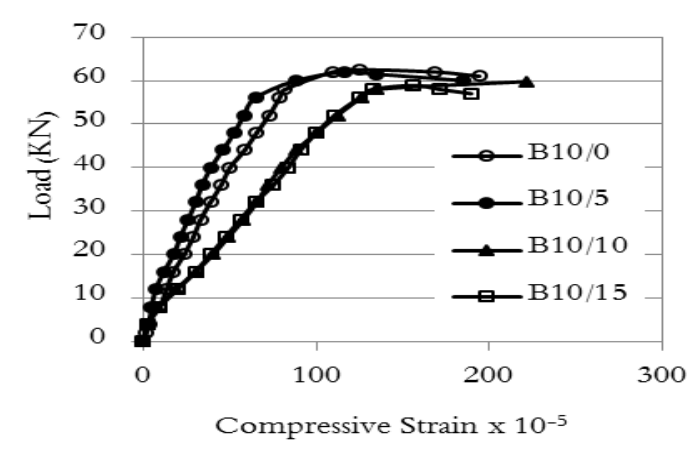

Fig. (12) Measured compressive strain $\left(d_{b}=10 \mathrm{~mm}\right)$

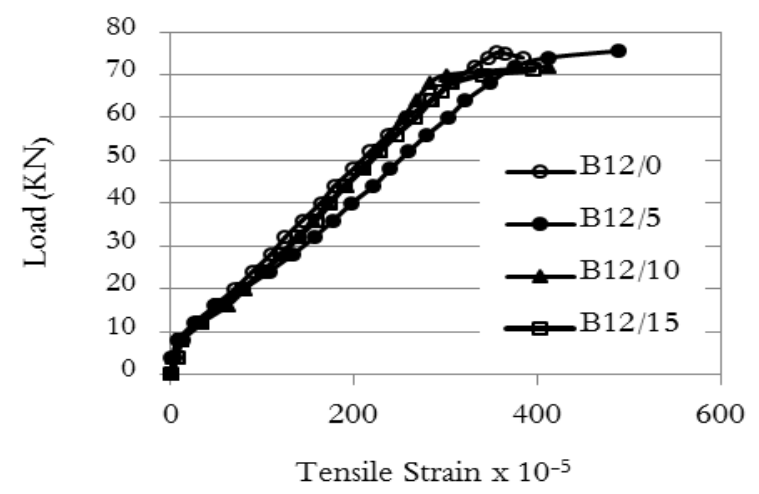

Fig. (10) Measured left side tensile strain $\left(\mathrm{d}_{\mathrm{b}}=12 \mathrm{~mm}\right)$

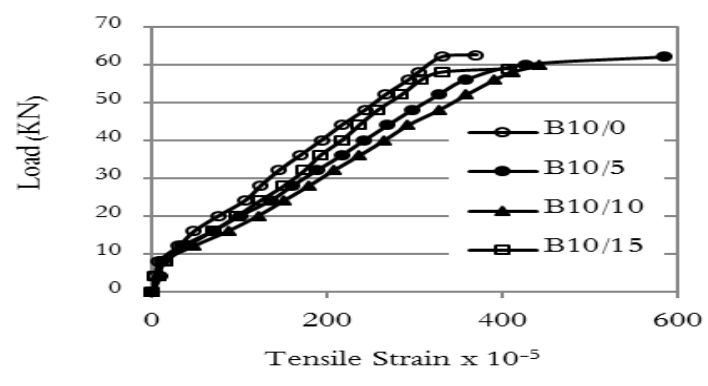

Fig. (9) Measured right side tensile strain $\left(d_{b}=10 \mathrm{~mm}\right)$

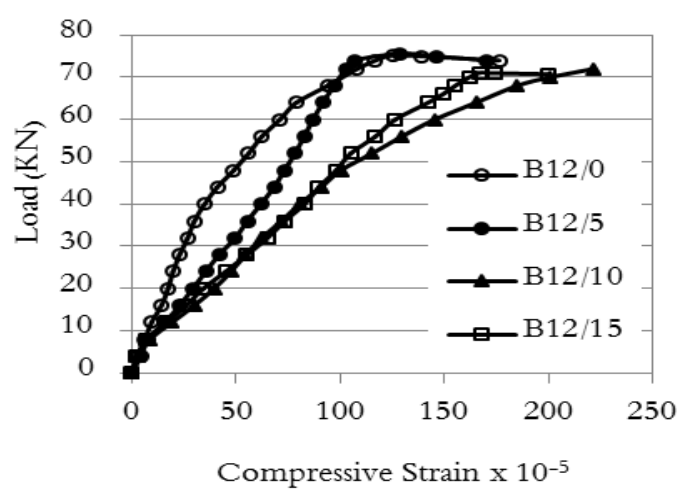

Fig. (13) Measured compressive strain $\left(d_{b}=12 \mathrm{~mm}\right)$

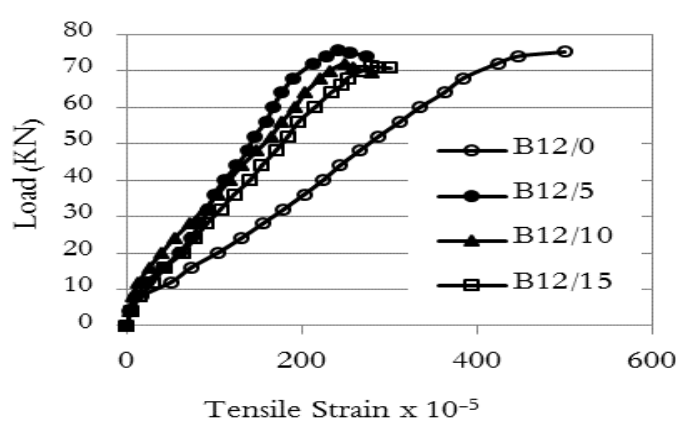

Fig. (11) Measured right side tensile strain $\left(d_{b}=12 \mathrm{~mm}\right)$

\subsection{Flexure Capacity}

The measured ultimate loads during the tests are reported in Table (4) along with the theoretical loads estimated by the ACI 318-08 [15] code equations for the flexure capacity. It can be seen that the theoretical loads were conservative and adequately estimated the ultimate loads independent of the used concrete mix.
The relative ultimate loads measurements are plotted in Figures $(14,15)$ to illustrate the influence of test parameters on the flexure capacity. Figures $(14,15)$ show that the reduction in the ultimate load due to DP replacement was 6 percent maximum when the replacement ratio was $15 \%$. The corresponding ratio was only $1 \%$ when the 
replacement ratio was $5 \%$. The reduction in the flexure capacity is an influence of the reduction in the compressive strength of concrete and this

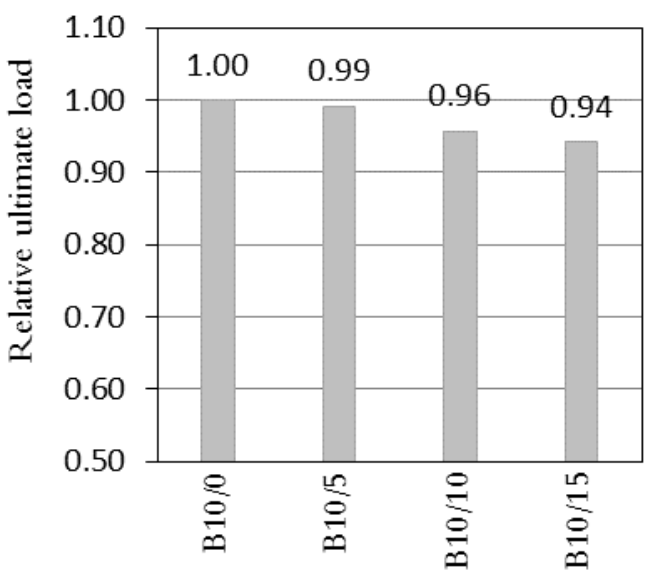

Fig. (14) Influence of the DP

replacement ratio $\left(d_{h}=10 \mathrm{~mm}\right)$ reduction could also be captured when the ACI 31808 equations were used to estimate the ultimate loads as can be seen in Table (4).

Table (4) Experimental failure loads and theoretical Ultimate loads for the test beams

\begin{tabular}{|c|c|c|c|c|}
\hline Group & Beam & $\begin{array}{c}\text { Exper. } \\
\text { Ultimate load } \\
(\mathrm{kN})\end{array}$ & $\begin{array}{c}\text { Theo.Ultimate } \\
\text { load } \\
(\mathrm{kN})\end{array}$ & $\begin{array}{c}\text { exp. ultimate } \\
\text { load / theo. } \\
\text { ultimate load }\end{array}$ \\
\hline A & B10/0 & 62.5 & 55.91 & 1.12 \\
\hline B & B10/5 & 62.0 & 55.87 & 1.11 \\
\hline C & B10/10 & 59.8 & 55.48 & 1.08 \\
\hline D & B10/15 & 58.9 & 54.94 & 1.07 \\
\hline A & B12/0 & 75.2 & 70.81 & 1.07 \\
\hline B & B12/5 & 75.6 & 70.74 & 1.03 \\
\hline C & B12/10 & 72.0 & 70.04 & \\
\hline D & B12/15 & 71.1 & 69.14 & \\
\hline
\end{tabular}

\section{5- CONCLUSIONS}

Based on the available test results the following conclusions can be drawn:

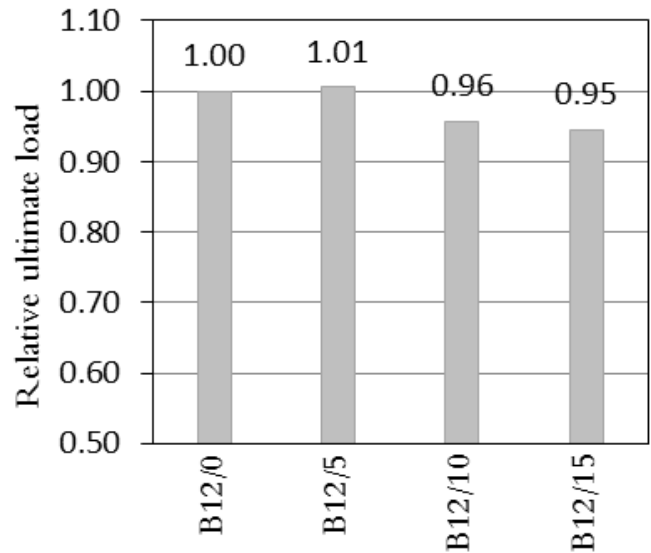

Fig. (15) Influence of the DP replacement ratio $\left(d_{b}=12 \mathrm{~mm}\right)$

1. The compressive strength of concrete tends to decrease as the dolomite powder replacement ratio increased. The compressive strength decreased at a reduced rate as the replacement ratio increased. 
2. Better consistency in terms of slump was obtained due to the incorporation of dolomite powder in the concrete mixes.

3. The structural performance of beams was not significantly influenced by the $5 \%$ dolomite powder replacement in terms of stiffness, flexure capacity, cracking characteristics and failure mode.

4. Higher dolomite powder ratios of 10 and 15 percent resulted in reduced stiffness and relatively larger tensile and compressive strains, while the cracking characteristics and failure mode were not changed.

\section{REFERENCES}

1. F. Puertas and M. Palacios, slag cement and concrete. Proceedings of the 1st International Conference "New Cements and their Effects on Concrete Performance" National Housing and Building and Research Center (HBRC) - Helwan University, Cairo, Egypt, (2008): 11 p.

2. ACI Committee 116R-00, American Concrete Institute, Cement and Concrete Terminology, 2000, Farmington Hills, Michigan.

3. ASTM C 150, American Society for Testing and Materials, "Specification for Portland Cement", June 2000.

4. EN 197-1, European cement standard, Part 1, 2000, "Composition, specifications and conformity criteria for common cements".

5. Egyptian Standards Specification, E.S.S, 47561/2009, (physical and mechanical properties examination of cement, part 1), Cairo, 2009.

6. Cement Association of Canada, "Portland Limestone Cement", Aug. 2009.

7. ECP 203-2007 (2007), "Egyptian Code for the design and construction of reinforced concrete structures", National Building and Research Center (HBRC), Cairo, Egypt 352 p.

8. Kamal MM, Safan MA, and Al-Gazzar MA, Blended Portland cements for low-cost self compacting concrete. Proceedings of the 1st International Conference "New Cements and their Effects on Concrete Performance" National Housing and Building and Research Center (HBRC) - Helwan University, Cairo, Egypt, (2008): 14 p.

9. Al-Gazzar M A, Low-cost self-compacting Concrete. PhD Thesis, Menoufia University, Egypt (2009): 243 p.

10. Safan MA, Shear strength of concrete beams cast with self-compacting concrete containing different fillers and coarse aggregates. Canadian Journal of Civil Engineering, 2012, 38(7): in press.

11. Safan MA, Performance of beams cast with lowcost self-compacting concrete in aggressive environment. Acta Polytechnica, 2011, 51(5): 120-130.

12. Hotton, R.D., Nokken, M.R., and Thomas, M.D.A. (2007), "Portland Limestone cement: State-of-the art Report and Gap Analysis for CSA A3000", cement Association of Canada Research and Development, report SN3053, 59p.

13. Thomas, M., Hotton, D., Cail, K., Smith, B., Wal. J. and Kazanis, K. (2010), "Field trials of concretes produced with Portland Limestone cement: New CSA cement type performs well in an aggressive environment", Concrete International, 34-41.

14. Elboghdady Amr, Structural behavior of concrete beams cast with blended cement, PhD Thesis, Menoufia University, Egypt (2014): 142 p.

15. ACI Committee 318. Building Code Requirements for structural concrete (318-08) and commentary. ACI 318R-08, 2008: 471p. 